\title{
MEASUREMENT OF SURFACE STRAIN-RATE ON TAKU GLAGIER, ALASKA
}

\author{
By T. H. Wu and R. W. Christensen
}

(Department of Civil Engineering, Michigan State University, East Lansing, Michigan, U.S.A.)

\begin{abstract}
Strain-rate and surface velocity measurements were made on a valley glacier. The measured strain-rates were used to calculate the stress condition and velocity distribution in the glacier. The measured velocity is in reasonable agreement with that calculated from Nye's plasticity solution.

RÉsumé. Des mesures de vitesse de déformation et de vitesse de surface ont été faites sur le Taku Glacier (Alaska). Les vitesses de déformation mesurées ont été utilisées pour calculer les conditions de tension et la distribution de vitesse dans le glacier. La vitesse mesurée est en accord raisonnable avec celle calculée à partir de la théorie de la plasticité de Nye.

Zusammenfassung. Am Taku-Gletscher in Alaska wurden Deformationsgeschwindigkeiten und Oberflächengeschwindigkeiten gemessen. Aus den gemessenen Deformationsgeschwindigkeiten wurde der Spannungszustand und die Geschwindigkeitsverteilung im Innern des Gletschers berechnet. Die gemessene Geschwindigkeit stimmt annehmbar mit der nach Nye's Plastizitätstheorie berechneten überein.
\end{abstract}

\section{INTRODUGTION}

This article presents the results of surface strain-rate and velocity measurements made on the Taku Glacier, a part of the Juneau Icefield in south-eastern Alaska. The icefield covers about $\mathrm{I}, 500$ square miles $\left(4,000 \mathrm{~km} .^{2}\right)$ of area with its upper névé at an elevation between 4 ,ooo and 7,000 ft. ( 1,200 and 2, $100 \mathrm{~m}$.). The Taku Glacier is one of the major valley glaciers of the icefield (Fig. I).

The objective of this study is to obtain information on the stress conditions in the glacier. Measurements were made at four points designated as A, B, C, D along the profile AA (Figs. I and 2). This is one of the several sites on the icefield where continuous records have been maintained on the surface velocity and accumulation. The bore-hole deformation measurements of $195^{0-53}$ were also made at this locality (Miller, I958).

\section{Strain-Rate Measurements}

The measurement of strain-rate followed the procedure outlined by Nye ( 1959). Squares with sides equal to Ioo ft. $(30 \cdot 5 \mathrm{~m}$.) were set on the glacier surface. The reference points were marked by wooden stakes driven into the firn. At each location, two squares were laid out in tandem as shown in Figure 3. The stakes had to be redriven after a io-day interval because of the large ablation. The distances between the reference points were taped before and after redriving. For each square, the measurements give the normal strain in four directions at angles of $\mathrm{o}, 45^{\circ}, 90^{\circ}$, and $135^{\circ}$ with the $\gamma$-axis (Figure 3 ). The $X$-axis is the direction of glacier flow, which is approximately S. $42^{\circ} \mathrm{E}$. at this location.

The measured strain-rates are summarized in Table I. The two strain-rates in each direction are averaged to obtain the strain-rate in that direction for the area covered by the square. The results are checked against the theoretical relationship

$$
\dot{\epsilon}_{0}+\dot{\epsilon}_{90}=\dot{\epsilon}_{45}+\dot{\epsilon}_{135}
$$

which holds if the variation in strain-rate is linear within the area of the square. However, the values in Table I indicate that this may not be the actual case. At AI and A2, the strain rates for the two halves of a square are very different and the quantity $\left(\dot{\epsilon}_{0}+\dot{\epsilon}_{90}\right)-\left(\dot{\epsilon}_{45}+\dot{\epsilon}_{135}\right)$ is quite large. This suggests the possibility that the measurements are not reliable. However, if we compare the individual strain-rates at any location for the intervals 2 I August to I September and I September to I I September, we find a high degree of consistency. By means of repeated measurements it was concluded that the errors in taping do not exceed $\pm \frac{1}{8}$ in. $(3 \mathrm{~mm}$.) which 


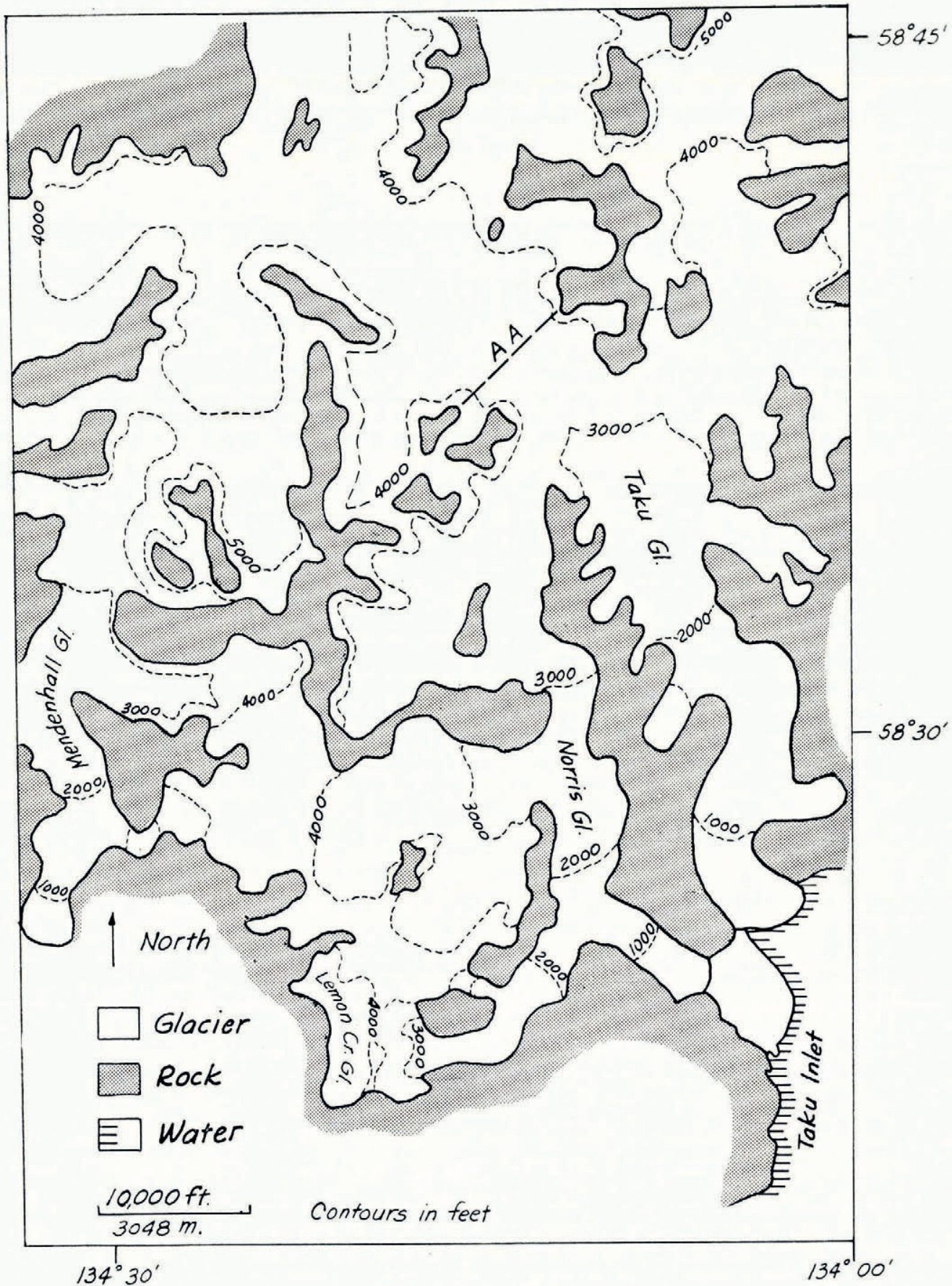

Fig. I. Part of the Funeau Icefield, Alaska 


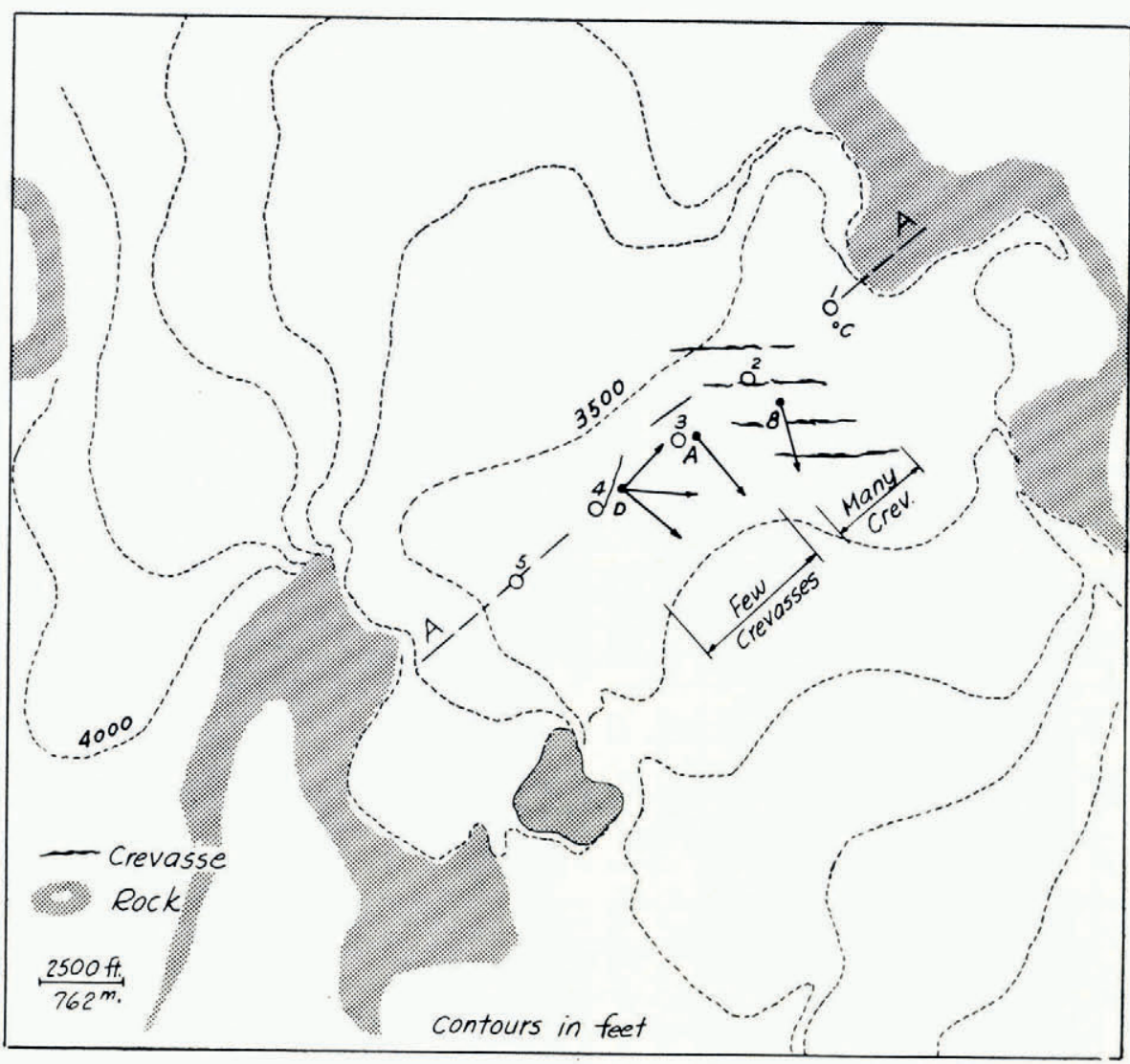

Fig. 2a. Location of velocity and strain-rate measurements

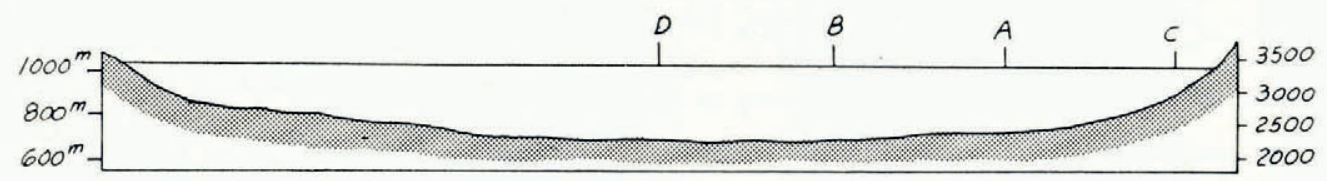

Horiz. scale $=$ Vert. scale

Fig. 2b. Bedrock profile along AA (after Poulter and others, 1949; Miller, 1952)

corresponds to a strain-rate of $0.07 \times \mathrm{IO}^{-5} \mathrm{hr} .^{-1}$. It is to be noted that with few exceptions the measured individual strain-rates during the two periods do not differ by more than $0 \cdot 15 \times \mathrm{IO}^{-5} \mathrm{hr}^{-1}$ at AI and A2. It is therefore our conclusion that the measured values are reliable.

At points B I and B2, the errors as measured by $\left(\dot{\epsilon}_{0}+\dot{\epsilon}_{90}\right)-\left(\dot{\epsilon}_{45}+\dot{\epsilon}_{135}\right)$ are about the same order of magnitude as those at AI and A2 but the strain-rates are much larger. However, 
Table I. Measured Strain-Rates $\left(\times 1 \mathrm{I}^{-5} \mathrm{hr} \cdot{ }^{-1}\right)$

$$
\begin{aligned}
& \text { Point Date } \\
& \begin{array}{llll}
\dot{\epsilon}_{0} & \dot{\epsilon}_{45} & \dot{\epsilon}_{90} & \dot{\epsilon}_{13}
\end{array} \\
& \text { AI } 21 \text { August to } \quad a_{1}=-0.298 \quad b_{1}=-0.270 \quad c_{1}=-0.111 \quad d_{1}=-0.118 \\
& \text { I September } a_{2}=+0.055 \quad b_{2}=+0.43 \mathrm{I} \quad c_{2}=+0.388 \quad d_{2}=+0.470 \\
& \text { average }-0.122 \quad+0.080 \quad+0.139 \quad+0.176+0.017-(0.256) \\
& \text { AI I September to } a_{1}=-0.250 \quad b_{1}=-0.309 \quad c_{1}=+0.125 \quad d_{1}=-0.177
\end{aligned}
$$

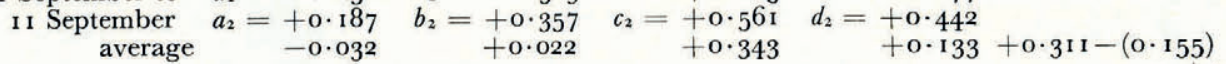

$$
\begin{aligned}
& \text { A2 } 21 \text { August to } \quad a_{1}=+0.442 \quad b_{1}=-0.039 \quad c_{1}=0 \quad d_{1}=+0.039
\end{aligned}
$$

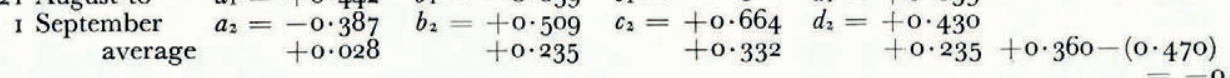

$$
\begin{aligned}
& \text { A2 I September to } a_{\mathrm{I}}=-0.373 \quad b_{\mathrm{I}}=\quad 0 \quad c_{\mathrm{I}}=-0.062 \quad d_{\mathrm{I}}=-0.177
\end{aligned}
$$

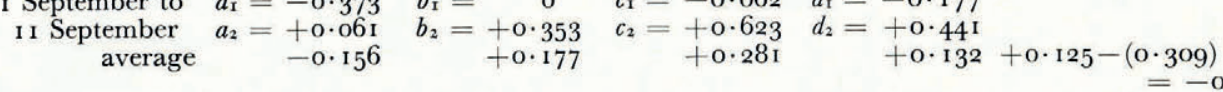

$$
\begin{aligned}
& \text { BI } 21 \text { August to } \quad a_{\mathrm{r}}=+0.39 \mathrm{I} \quad b_{\mathrm{r}}=-0.67 \mathrm{I} \quad c_{\mathrm{r}}=+\mathrm{0} \cdot 334 \quad d_{\mathrm{r}}=+\mathrm{r} \cdot 380
\end{aligned}
$$

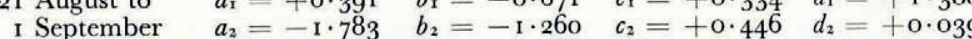

$$
\begin{aligned}
& \text { average }-0.696 \quad-0.966 \quad+0.390 \quad+0.710-0.306-(-0.256) \\
& \text { BI } \begin{array}{cc}
\text { I September to } \\
\text { II September } \\
\text { average }
\end{array} \begin{array}{c}
a_{1}=-0 \cdot 187 \\
a_{2}=-1 \cdot 491 \\
\end{array} \\
& b_{\mathrm{r}}=-0 \cdot 703 \\
& c_{1}=+0 \cdot 745 \quad d_{1}=+0 \cdot 703 \\
& c_{2}=+0 \cdot 455 \quad d_{2}=+0 \cdot 308 \\
& -0.682+0.600 \\
& b_{\mathrm{I}}=-0 \cdot 473 \\
& \begin{aligned}
b_{2}= & -\mathrm{I} \cdot 145 \\
& -0 \cdot 809
\end{aligned} \\
& d_{\mathrm{I}}=+\mathbf{0} \cdot 395 \\
& +1 \cdot 005 \\
& b_{\mathrm{I}}=-\mathrm{I} \cdot 100 \\
& \begin{aligned}
b_{2}= & -1 \cdot 276 \\
& -1 \cdot 188
\end{aligned} \\
& d_{\mathrm{I}}=+0 \cdot 835 \\
& +\mathbf{r} \cdot 026 \\
& \begin{aligned}
d_{2}= & +1 \cdot 540 \\
& +\mathrm{r} \cdot 188+0 \cdot 216-0
\end{aligned} \\
& b_{1}=+0.592 \quad c_{1}=+0.61_{5} \quad d_{1}=+0.510
\end{aligned}
$$

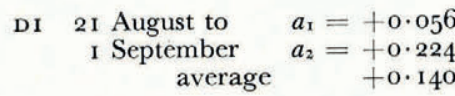

$$
\begin{aligned}
& \begin{aligned}
b_{2}= & +0.116 \\
& +0.354
\end{aligned} \\
& \begin{aligned}
c_{1}= & +0.615 \\
c_{2}= & +0.056 \\
& +0.336
\end{aligned} \\
& d_{2}=+0.158 \\
& +0.334+0.476-(0.688) \\
& b_{1}=+0 \cdot 74^{8} \quad c_{1}=+0 \cdot 745 \quad d_{1}=+0 \cdot 57^{2} \\
& \text { DI } \begin{array}{cc}
\text { I September to } \\
\text { I I September } \\
\text { average }
\end{array} \begin{array}{c}
a_{1}=+0 \cdot 28 \\
a_{2}=
\end{array} \\
& \begin{aligned}
b_{2}= & +0.352 \\
& +0.550
\end{aligned} \\
& \begin{aligned}
c_{2}= & +0 \cdot 249 \\
& +0.497
\end{aligned} \\
& \begin{array}{l}
d_{1}=+0 \cdot 572 \\
d_{2}=+0 \cdot 5^{28}
\end{array} \\
& +0 \cdot 55^{\circ}+0 \cdot 857-(\mathbf{I} \cdot \mathbf{1 0 0}) \\
& b_{1}=-0.039 \quad c_{\mathrm{r}}=+0.112 \quad d_{1}=-0.473 \\
& \text { D2 } 21 \text { August to } \quad a_{\mathrm{I}}=+0 \cdot 192 \\
& \begin{array}{c}
\text { I September } \\
\text { average }
\end{array} \quad \begin{array}{ll}
a_{2}= & -0.415 \\
& -0.112
\end{array} \\
& \begin{aligned}
b_{2}= & -0.279 \\
& -0.158
\end{aligned} \\
& \begin{aligned}
c_{1}= & +0.112 \\
c_{2}= & -0.895 \\
& -0.392
\end{aligned} \\
& \begin{array}{l}
d_{1}=-0.473 \\
d_{2}=-0.513
\end{array} \\
& -0.493-0.504-(-0.651) \\
& b_{1}=+0.088 \quad c_{1}=-0.062 \quad d_{1}=00
\end{aligned}
$$

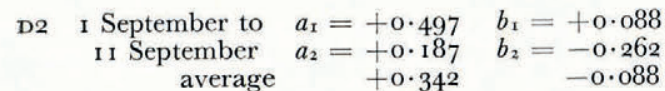

$$
\begin{aligned}
& \begin{aligned}
c_{1}= & -0 \cdot 062 \\
c_{2}= & -0 \cdot 435 \\
& -0 \cdot 249
\end{aligned} \\
& =-0.050 \\
& =-0.06 \\
& =+0.184 \\
& =-0 \cdot 243 \\
& =+0 \cdot 147 \\
& \begin{array}{l}
d_{1}=0 \\
d_{2}=+0 \cdot 088
\end{array} \\
& +0 \cdot 044+0 \cdot 093-(-0.044)
\end{aligned}
$$

considerable differences are observed between the individual strain-rates $\left(a_{\mathrm{I}}, a_{2}, b_{\mathrm{I}}, b_{2}, \ldots\right)$ measured during the two time intervals. These differences may be the reflection of the irregular crevasse movements.

The results from points DI and D2 are difficult to analyze. The strain-rates changed considerably during the time intervals, especially at D2. Hence it is not possible to use the argument advanced for the measurements at AI and A2 and we must admit that the measurements may not be dependable. The measured strain-rate at GI is equal to zero. At C2 the distance changes measured during the two time intervals are about $\pm_{4}^{1} \mathrm{in}$. $(6 \mathrm{~mm}$.). A substantial part of this is likely to be due to taping errors. Hence it is concluded that little or no strain exists at $\mathrm{c}$. 

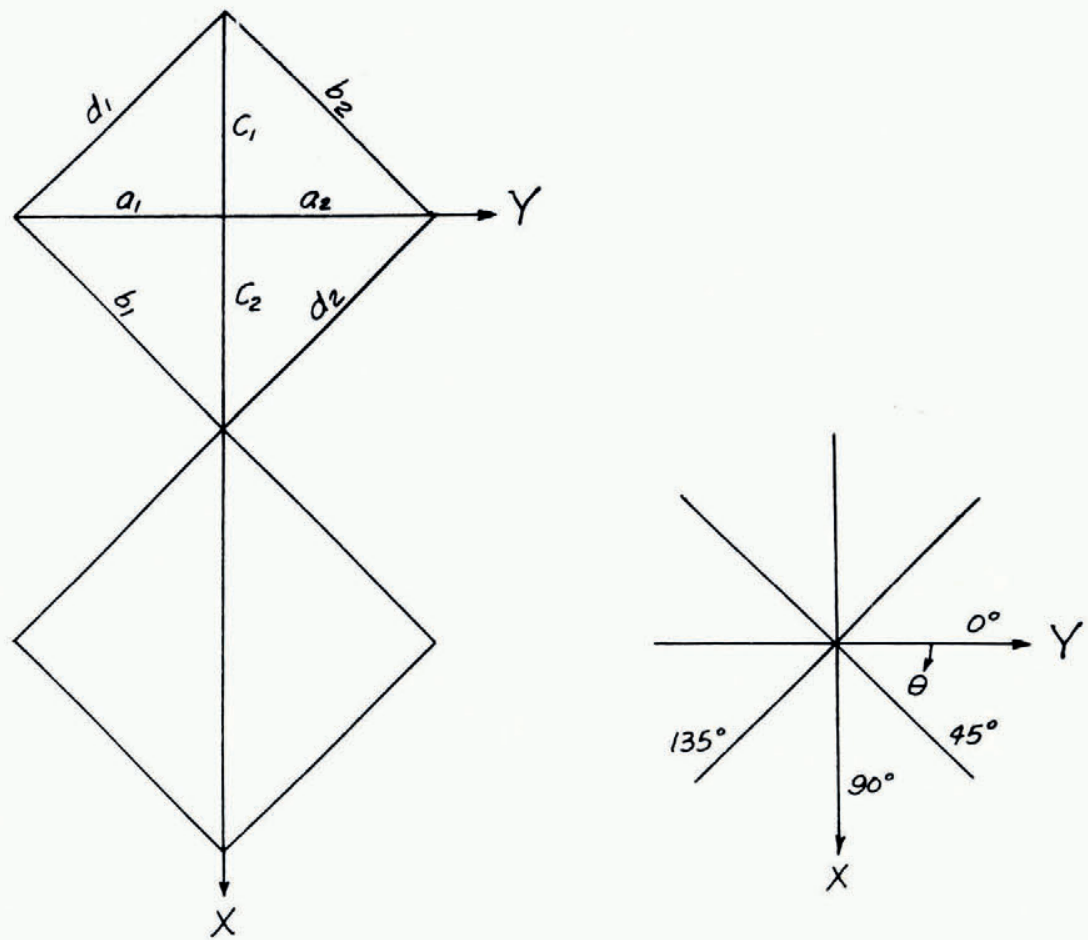

Fig. 3. Squares for strain-rate measurements

\section{Stresses and Crevasse Patterns}

The measured strain-rates $\dot{\epsilon}_{0}, \dot{\epsilon}_{45}, \dot{\epsilon}_{90}, \dot{\epsilon}_{135}$ are used to calculate the strain-rates in the directions parallel $(X)$ and perpendicular $(Y)$ to that of glacier flow (Figure 2). The best fit values of $\dot{\epsilon}_{x}, \dot{\epsilon}_{y}, \dot{\epsilon}_{x y}$ by the principle of least squares have been shown to be (Nye, I959, I957 [b], p. $\left.{ }^{5} 5-63\right)$

$$
\begin{aligned}
\dot{\epsilon}_{x} & =-\frac{1}{4} \dot{\epsilon}_{0}+\frac{1}{4} \dot{\epsilon}_{45}+\frac{3}{4} \dot{\epsilon}_{90}+\frac{1}{4} \dot{\epsilon}_{135}, \\
\dot{\epsilon}_{y} & =\frac{3}{4} \dot{\epsilon}_{0}+\frac{1}{4} \dot{\epsilon}_{45}-\frac{1}{4} \dot{\epsilon}_{90}+\frac{1}{4} \dot{\epsilon}_{135}, \\
\dot{\epsilon}_{x y} & =\frac{1}{2} \dot{\epsilon}_{45}-\frac{1}{2} \dot{\epsilon}_{\mathrm{I} 35} .
\end{aligned}
$$

\begin{tabular}{|c|c|c|c|c|c|c|c|c|}
\hline Point & Date & $\dot{\epsilon}_{x}$ & $\epsilon_{y}$ & $\epsilon_{x y}$ & $\dot{\epsilon}_{1}$ & $\epsilon_{2}$ & $\dot{\epsilon}_{3}$ & $\theta$ \\
\hline AI & 2 I August to I September & $+\mathbf{o} \cdot \mathbf{1} 99$ & $-0 \cdot 063$ & +0.048 & +0.21 & -0.14 & -0.07 & $98 \cdot 7^{\circ}$ \\
\hline AI & I September to I I September & +0.305 & -0.071 & +0.055 & $+0.3 I$ & $-0 \cdot 23$ & $-0 \cdot 08$ & $97 \cdot 7^{\circ}$ \\
\hline A2 & 2 I August to I September & $+0 \cdot 360$ & $+0 \cdot 05^{6}$ & o & +0 & $-0 \cdot 30$ & -0 & $90^{\circ}$ \\
\hline \multirow[t]{2}{*}{ A2 } & I September to I I September & +0.327 & $-0 \cdot 110$ & $-0 \cdot 022$ & $+0 \cdot 33$ & $-0 \cdot 22$ & $-0 \cdot$ I I & $87 \cdot 2^{\circ}$ \\
\hline & aver & +0.298 & -0.047 & +0.041 & & $-0 \cdot 22$ & $-0 \cdot 09$ & \\
\hline B1 & 2 I August to I September & $+0 \cdot 055$ & $-0 \cdot 862$ & +0.838 & $+0 \cdot 56$ & $+0 \cdot 80$ & $-\mathrm{r} \cdot 36$ & $120 \cdot 5^{\circ}$ \\
\hline B I & I September to i i Sep & $+0 \cdot 6$ I 6 & $-0 \cdot 823$ & +0.594 & $+0 \cdot 84$ & $+0 \cdot 19$ & $-\mathrm{I} \cdot 03$ & $109 \cdot 5^{\circ}$ \\
\hline B2 & 2 I August to I September & $+0 \cdot 959$ & $-0 \cdot 827$ & +0.828 & $+\mathrm{I} \cdot 30$ & -0.15 & $-\mathrm{I} \cdot \mathrm{I} 5$ & I I I $\cdot 0^{\circ}$ \\
\hline \multirow[t]{2}{*}{ B2 } & I September to I I September & $+0 \cdot 5^{64}$ & $-0 \cdot 865$ & $+\mathbf{I} \cdot \mathbf{r} 88$ & $+1 \cdot 23$ & $+0 \cdot 29$ & $-I \cdot 5^{2}$ & $119 \cdot 0^{\circ}$ \\
\hline & & $+0 \cdot 549$ & $-0 \cdot 844$ & +0.862 & +0.97 & $+0 \cdot 30$ & $-1 \cdot 5^{2}$ & $115 \cdot 5$ \\
\hline DI & 2 I August to I Sep & $+0.39^{\circ}$ & $+0 \cdot 194$ & -0.005 & +0.39 & $-0 \cdot 5^{8}$ & $+0 \cdot 19$ & $90^{\circ}$ \\
\hline DI & I September to i i Sep & +0.563 & $+0 \cdot 422$ & o & +0.57 & -0.99 & $+0 \cdot 4^{2}$ & $90^{\circ}$ \\
\hline D2 & 2 I August to I Septem & $-0 \cdot 239$ & $-0 \cdot 149$ & $-0 \cdot 169$ & $-0 \cdot 02$ & +0.39 & -0.37 & $52^{2}$ \\
\hline D2 & I September to I I September & $-0 \cdot 284$ & $+0 \cdot 308$ & -0.022 & $+0 \cdot 3^{1}$ & -0.03 & $-0 \cdot 28$ & $180^{\circ}$ \\
\hline
\end{tabular}

Table II. Measured Principal Strain-Rates $\left(\times 10^{-5} \mathrm{hr}^{-1}\right)$ 
The major and minor principal strains $\dot{\epsilon}_{\mathrm{I}}$ and $\dot{\epsilon}_{3}$ and their directions are calculated graphically by means of Mohr's circle of strain. The angle between the $X$-axis and the $\dot{\epsilon}_{\mathrm{I}}$ vector is denoted by $\theta$ (see Figure 3 for sign). Assuming no volume change, the intermediate principle strain $\dot{\epsilon}_{2}$ is determined by means of the relationship

$$
\dot{\epsilon}_{1}+\dot{\epsilon}_{2}+\dot{\epsilon}_{3}=\text { o. }
$$

The results of the calculations are given in Table II.

In order to obtain some indication of the general stress conditions in the glacier, the measured values are averaged to give an average strain-rate at each site. This is not done at D because of the erratic variations in the measured strain-rate. The stresses are calculated from the average strain-rates by the use of the relationship between stress and strain-rate obtained by Glen (r955) from laboratory creep tests on ice.

Nye (r953) defined $\dot{\epsilon}$ and $\tau$ as follows

$$
\dot{\epsilon}=B \tau^{n} \text {. }
$$

and

$$
\dot{\epsilon}^{2}=\frac{1}{2} \dot{\epsilon}_{i j} \dot{\epsilon}_{i j}
$$

$$
\tau^{2}=\frac{1}{2} \sigma_{i j}^{\prime} \sigma_{i j}^{\prime}
$$

in which $\dot{\epsilon}_{i j}$ and $\sigma_{i j}^{\prime}$ are the components of the strain-rate and stress deviator tensors. The constants $B$ and $n$ are equal to $0 \cdot 14^{8} \mathrm{yr}^{-1} \operatorname{bar}^{-n}$ and $4 \cdot 2$, respectively. The stress deviator is then obtained from the relationship

$$
\sigma_{\mathrm{I}}^{\prime}=\frac{\tau}{\dot{\epsilon}} \dot{\epsilon}_{\mathrm{I}}, \quad \sigma_{2}^{\prime}=\frac{\tau}{\dot{\epsilon}} \dot{\epsilon}_{2}, \quad \sigma_{3}^{\prime}=\frac{\tau}{\dot{\epsilon}} \dot{\epsilon}_{3} .
$$

The principal stresses are

$$
\sigma_{\mathrm{I}}=2 \sigma_{\mathrm{I}}^{\prime}+\sigma_{3}^{\prime}, \quad \sigma_{2}=0, \quad \sigma_{3}=\sigma_{\mathrm{I}}^{\prime}+2 \sigma_{3}^{\prime} .
$$

\begin{tabular}{|c|c|c|c|c|c|c|c|c|c|}
\hline \multirow[b]{2}{*}{ Point } & \multicolumn{4}{|c|}{ Strain-rates $\left(\mathrm{yr}^{-1}\right)$} & \multicolumn{5}{|c|}{ (Stresses bars) } \\
\hline & $\dot{\boldsymbol{\epsilon}}_{\mathrm{I}}$ & $\dot{\epsilon}_{2}$ & $\dot{\epsilon}_{3}$ & $\dot{\epsilon}$ & $\tau$ & $\sigma_{1}$ & $\sigma_{3}$ & $\tau_{x y}$ & $\sigma_{x}$ \\
\hline A & +0.0267 & -0.0223 & $-0 \cdot 0044$ & $0.035^{1}$ & 0.800 & $+\mathrm{I} \cdot \mathrm{I} \mathbf{1} 8$ & +0.409 & o & $1 \cdot 118$ \\
\hline B & +0.0868 & +0.0244 & -0.1112 & 0.1013 & 0.915 & +0.565 & $-\mathrm{I} \cdot 225$ & 0.680 & $I \cdot 230$ \\
\hline
\end{tabular}

When the principal stresses are not in the $X-Y$ directions, the stresses $\sigma_{x}, \sigma_{y}$ and $\tau_{x y}$ are calculated by Mohr's circle. The results of stress calculations are given in Table III.

Table III. Stresses Calculated from Measured Strain-Rates

Nye (1952, 1959) and Ward (1955, p. 594) have shown that crevasses in glaciers are the result of tensile stresses and that they run in a direction perpendicular to that of the maximum tensile stress. To compare the stress conditions with the crevasse patterns, the directions of the measured major principal strain-rates at A, B, and D are plotted as vectors in Figure 2, together with the directions of the crevasses. The general agreement is considered satisfactory. On the other hand, Meier (1958) observed at Blue Ice Valley, Greenland, that crevasses in firn form at an angle to the trajectories of maximum principal strain-rate. This does not appear to be the case on the Taku Glacier. It should be added that site в is located in an area of numerous crevasses, many of them are 3 or $4 \mathrm{ft}$. $\left(0 \cdot 9^{-\mathrm{I}} \cdot 2 \mathrm{~m}\right.$.) wide and over $5^{\mathrm{o}} \mathrm{ft}$. ( $15 \mathrm{~m}$.) deep. At sites $\mathrm{A}$ and $\mathrm{D}$ only a few crevasses are observed. These are only fine cracks in the snow that are noticeable only at very short distances.

\section{Surface Velocity}

The surface velocity was measured during the summer of 1962 along the same profile by triangulation with a theodolite (Miller, 1954). Figure 4 shows the velocity obtained at five points on two lines $500 \mathrm{ft}$. ( $152 \mathrm{~m}$.) apart. The location of points $\mathrm{I}$ through 5 are shown in 
Figure 2. The velocity measured along the two lines are almost identical with the exception of point 4 . The value obtained for point 4 on the left line (Figure 4 ) appears to be too small and is discarded in subsequent calculations. The average direction of the velocity vectors is $\mathrm{S} .42^{\circ} \mathrm{E}$. The velocity measurements also show very little movement near point c. Hence we come to the conclusion that the ice immediately adjacent to the valley walls is not moving at any observable rate.

To calculate the velocity in a glacier subjected to longitudinal tension, use is made of the plasticity solution by Nye (1957[a]). For the stress-strain relationship given in Equation (3), the dimensionless velocity $U$ is

$$
U=U_{0}-\frac{2}{n+\mathrm{I}}\left[T^{n+1}-(n+\mathrm{I}) T^{\mathrm{I}-n}+n\right]+X
$$

in which $T$ is the dimensionless shear-stress related to the dimensionless distance $r$ as follows

The dimensionless variables are

$$
T^{n-1}=\frac{\mathrm{I}}{\left[T^{2}-Y^{2}\right]^{\frac{1}{2}}}
$$

$$
T=\frac{\tau}{\tau_{0}}, \quad X=\frac{x}{l_{0}}, \quad Y=\frac{y}{l_{0}}, \quad U=\frac{u}{n_{0} l_{0}}
$$

in which

$$
n_{\mathrm{o}}=B\left(\tau_{0}\right)^{n}, \quad l_{0}=\tau_{\mathrm{o}} / \beta .
$$

The term $n_{0}$ denotes the surface longitudinal strain-rate and $\beta$ is the rate of change of $\tau_{x y}$ with $y$. In Nye's case of vertical velocity distribution in an infinitely wide glacier, $\beta$ is equal to $\rho g_{x}$, the component of the gravity force along the bed, and $y$ denotes the depth below the glacier surface. In the present case, equation (8) and (9) are used to calculate the horizontal velocity distribution. Then $y$ denotes the horizontal distance in the direction perpendicular to that of glacier flow. The $x$ direction is that of glacier flow.
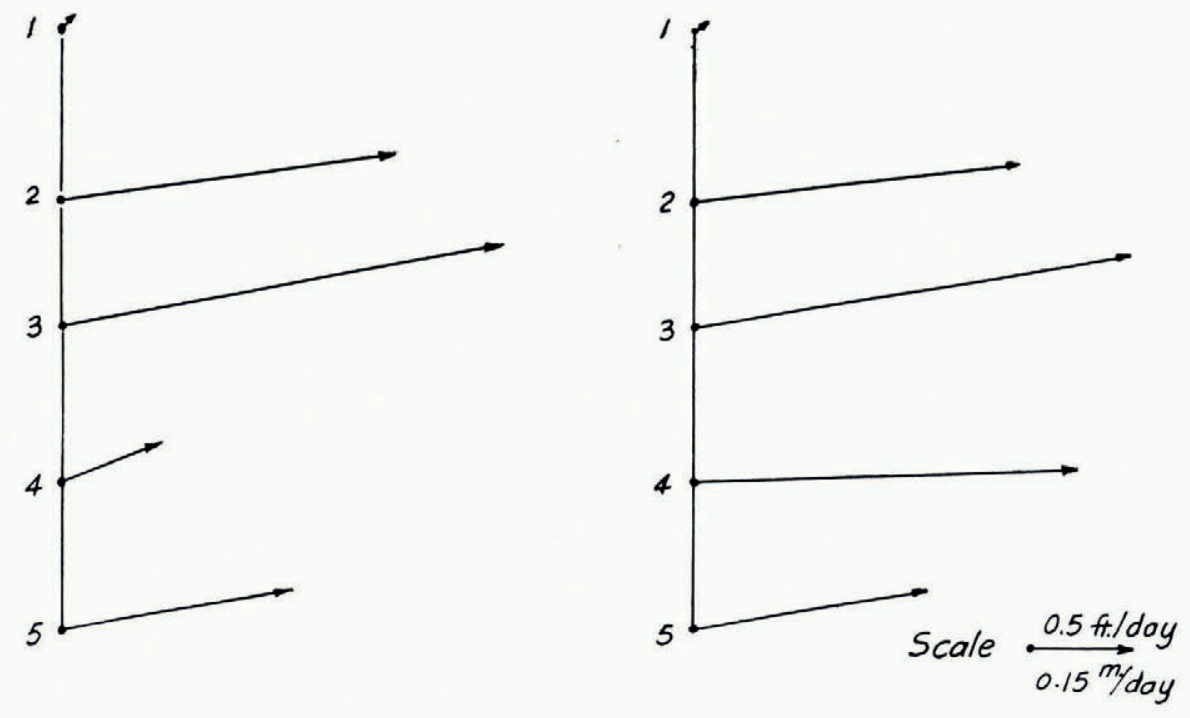

Fig. 4. Measured velocity along AA 
To calculate the surface velocity distribution across the glacier we make use of the measured shear stress $\tau_{x y}$. It is $0.68 \mathrm{bar}$ at в. If the shear stress varies linearly with $y, \tau_{x y}$ should be between $I \cdot O$ and $I \cdot 5$ bars at the edge of the moving ice. The shear-stress distributions for these two cases are shown as solid lines in Figure $5 \mathrm{~b}$. With a longitudinal strain-rate of $0 \cdot 550 \times \mathrm{IO}^{-5} \mathrm{hr}^{-1}$, the calculated velocity profiles for $X=0$, and $\tau_{x y}=\mathrm{I} \cdot 0$ and $\mathrm{I} \cdot 2$ bars at the edge are shown in Figure $5^{\mathrm{a}}$ as dashed curves. Since the velocity is very sensitive to the value of $\tau_{x y}$, the agreement is considered satisfactory. Because of the great sensitivity of the velocity to $\tau_{x y}$ it is more instructive to compare the velocity distribution across the glacier rather than the absolute quantities. The velocity distributions for $\tau_{x y}$ equal to $\mathrm{I} \cdot \mathrm{o}$ and $\mathrm{I} \cdot 5$ bars assuming that the velocity at the center is equal to the measured value of $820 \mathrm{ft}$./ $\mathrm{yr}$. $(250 \mathrm{~m}$./yr.) are shown as solid curves in Figure 5a. The agreement with the observed velocity distribution is very close.

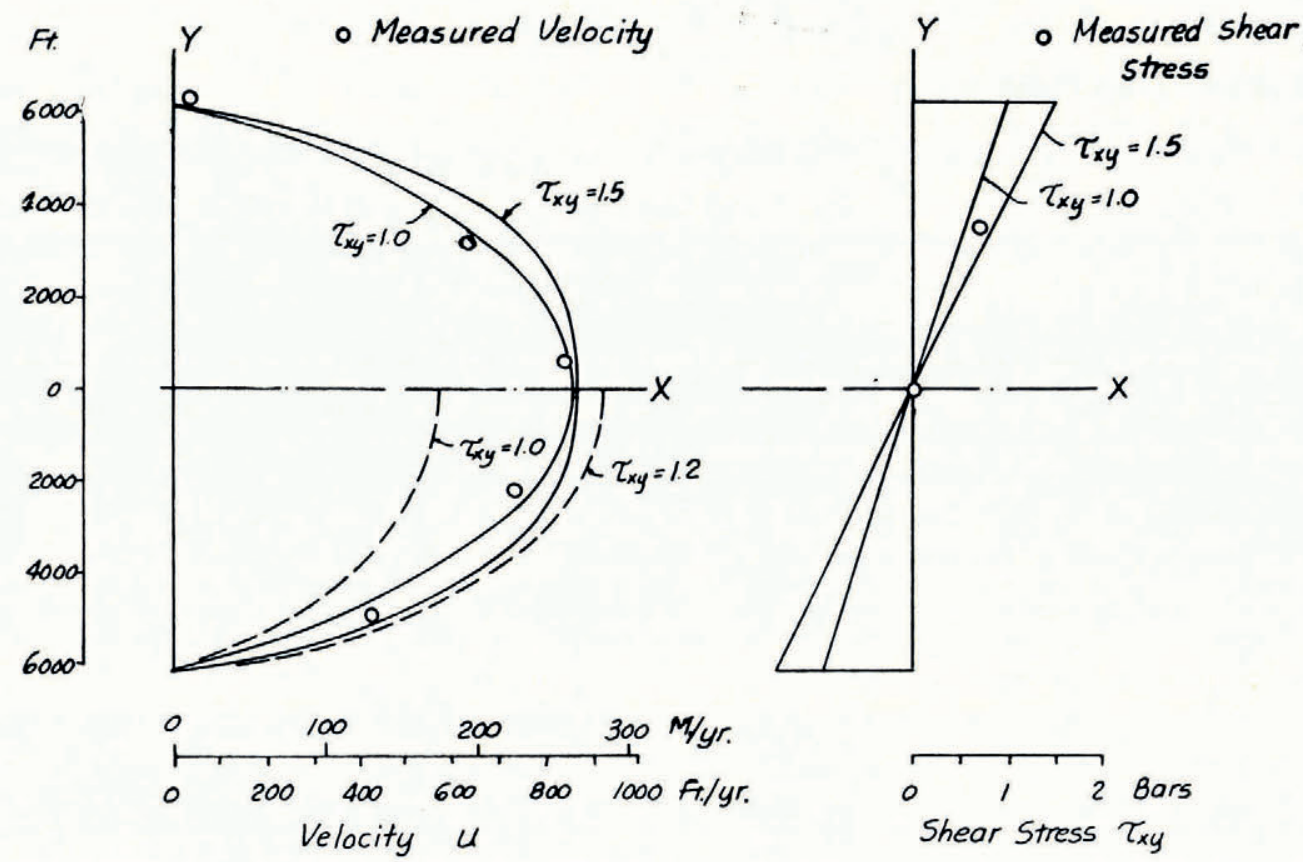

Fig. $5 a$ (left). Calculated and measured velocities

Fig. $5^{b}$ (right). Measured and assumed shear stresses

The plasticity solution used in the longitudinal velocity calculation also gives a transverse velocity. (In Nye's paper, this is the vertical velocity.) This transverse velocity is of the order of $200 \mathrm{ft}$./yr. $(6 \mathrm{I} \mathrm{m}$./yr.) which is appreciable. Whether this velocity can be attained at this site is indeterminate at present because of the irregularities in the valley and the many small tributaries that join the Taku glacier.

Finally it must be noted that the values of $B$ and $n$ used in all stress and velocity calculations are those obtained by Glen in laboratory tests. Their general agreement with field values have been demonstrated by Nye (1953). Nevertheless, considerable variations from these values are certainly possible as indicated by the bore-hole measurements of Miller (1958). Therefore, the calculated stress and velocity should be considered as reasonable approximations only. 


\section{SumMary}

The strain-rate measurements show that the glacier is subjected to a tensile stress in the longitudinal direction estimated to be about I bar. The shear stress between the glacier and the valley wall is of the order of $I_{1} \cdot 2$ bars.

The measured strain-rates are in general agreement with the crevasse patterns and the measured surface velocity.

Several questions remain unresolved. First among them is the very erratic variations of the surface strain-rate. A problem yet to be investigated is the extent to which strain-rates measured on the firn reflect the actual stress and strain-rate in the glacier ice. Also, the effect of large crevasses on the surface strain-rate is not determined. As some of the crevasses are $5^{0} \mathrm{ft}$. ( $15 \mathrm{~m}$.) or more deep, nonhomogeniety is certainly introduced by their presence.

\section{Acknowledgement}

The measurements were made as a part of the Juneau Icefield Research Program during the summer of 1963 . Funds for the activities were provided by the Foundation for Glacier Research and the National Science Foundation. The writers are grateful to the members of the I 963 expedition, particularly its director, Dr. M. M. Miller, for their co-operation that made this study possible.

MS. received 6 February 1964

\section{REFERENCES}

Glen, J. W. 1955. The creep of polycrystalline ice. Proceedings of the Royal Society, Ser. A, Vol. 228, No. 1175 , p. $5^{19-38}$

Meier, M. F. 1958. The mechanics of crevasse formation. Union Géodésique et Géophysique Internationale. Association Internationale d'Hydrologie Scientifique. Assemblée générale de Toronto, 3-14 sept. 1957. Tom. 4, p. 500-08.

Miller, M. M. 1952. Scientific observations of the Juneau Ice Field Research Project, Alaska, I949 field season, American Geographical Society. Juneau Ice Field Research Project. Report No. 6.

Miller, M. M. 1954. Juneau Ice Field Research Project, Alaska, 1950 summer field season. American Geographical Society. Juneau Ice Field Research Project. Report No. 7.

Miller, M. M. 1958. Phenomena associated with the deformation of a glacier bore hole. Union Géodésique et Géophysique Internationale. Association Internationale d'Hydrologie Scientifique. Assemblée générale de Toronto, $3^{-14}$ sept. 19.57. Tom. 4, p. $437-52$.

Nye, J. F. 1952. The mechanics of glacier flow. Journal of Glaciology, Vol. 2, No. 12, p. 82-93.

Nye, J. F. 1953. The flow law of ice from measurements in glacier tunnels, laboratory experiments and the Jungfraufirn borehole experiment. Proceedings of the Royal Society, Ser. A, Vol. 219, No. I I39, p. 477-89.

Nye, J. F. 1957[a]. The distribution of stress and velocity in glaciers and ice-sheets. Proceedings of the Royal Society, Ser. A, Vol. 239, No. 1216 , p. $113-33$.

Nye, J. F. 1957 [b]. Physical properties of crystals. Oxford, Clarendon Press.

Nye, J. F. 1959. A method of determining the strain-rate tensor at the surface of a glacier. Fournal of Glaciology, Vol. 3 , No. 25, p. 409-19.

Poulter, T. C., and others. 1949. Seismic measurements on the Taku Glacier, by T. C. Poulter, C. F. Allen and S. W. Miller. Stanford, Calif., Stanford Research Institute.

Ward, W. H. 1955. Studies in glacier physics on the Penny Ice Cap, Baffin Island, 1953. Part IV. The flow of Highway Glacier. Journal of Glaciolsgy, Vol. 2, No. 18, p. 592-99. 